\title{
On a New Expression for the Diurnal Variation of Air Temperature
}

\author{
By S. Azuma \\ Saikyo University, Kyoto \\ (Manuscript received 22 September, 1956)
}

\begin{abstract}
A new expression $A_{0}+A \sin (\sigma t-\gamma \sin \sigma t+\varepsilon)$ is suggested by the author to show the diurnal variation of air temperature. Method for finding the four constants $A_{0}, A, \gamma$ and $\varepsilon$ is given and its applicability and the degree of approximation are discussed by some actual data. Physical remarks and some applications to climatology are also given in this paper. A noticeable success is the discovery of an expression with only the diurnal single period, not containing the semi-diurnal or other higher harmonic periods which are of no physical significance.
\end{abstract}

\section{Contents}

\& 1. Introduction

§ 2. Method of Reduction

\&3. Physical and Meteorological Remarks

\& 4. Application to Climatology

\&. Summary

\section{§ 1. Introduction}

It is well known that the diurnal characteristic of air temperature is a best indicator of the local climatological conditions. The daily mean temperature together with the maximum and minimum values is listed in almost all climatological tables, and the times of maximum and minimum temperatures are added in some of these tables. The description of these data gives a primary idea of the diurnal characteristic; however, the more complete expressions are desired.

Adopting the method of harmonic analysis, we can express the diurnal variation of air temperature in the form of a Fourier series and its intrinsic nature enables itself to be expressed approximately with sufficient accuracy by the first three terms of the series, namely,

$$
\theta \approx a_{0}+r_{1} \sin \left(\sigma t+\delta_{1}\right)+r_{2} \sin \left(2 \sigma t+\delta_{2}\right)
$$

where $\sigma=2 \pi / T$ and $T=24$ hours. Thus the temperature variation can be defined by the five harmonic constants $a_{0}, r_{1}, r_{2}, \delta_{1}$ and $\delta_{2}$.

The present writer proposes a new approxi- mate expression of the type

$$
\theta=A_{0}+A \sin (\sigma t-\gamma \sin \sigma t+\varepsilon)
$$

which can be defined by the four constants $A_{0}, A, \gamma$ and $\varepsilon$. The applicability and utilization of this expression are discussed in the following sections.

\section{§2. Method of Reduction}

Now we illustrate the working method to derive the four constants from the hourly data of the diurnal variation of air temperature. The illustration is carried out by employing an example from N. K. Johnson's data at Leafield [1]*.

The hourly values $\left(\theta_{i}\right)$ are listed in Column II of Table 1.

(i) The constants $A_{0}$ and $A$ can be derived easily from the maximum $(M)$ and minimum $(m)$ values by the aid of the relations

or

$$
\begin{array}{ll}
A_{0}+A=M, & A_{0}-A=m \\
A_{0}=\frac{M+m}{2}, & A=\frac{M-m}{2} .
\end{array}
$$

* The numbers in brackets refer to the references listed at the end of the paper. 
For this example, $M=11.6^{\circ} \mathrm{C}, \quad m=6.2^{\circ} \mathrm{C}$ and hence $A_{0}=8.9^{\circ} \mathrm{C}, A=2.7^{\circ} \mathrm{C}$.

(ii) Calculate the values of $\theta_{i}-A_{0}$ and $\theta_{i}-A_{0} / A$ which are listed in Cols. III and IV respectively.

(iii) Find $\sin ^{-1} \frac{\theta_{i}-A_{0}}{A}(\mathrm{Col} . \mathrm{V})$ which must be equal to $\sigma t-\gamma \sin \sigma t+\varepsilon$.

(iv) Referring the values of $\sigma t$ (Col. VI), calculate $\sigma t-\sin ^{-1} \frac{\theta_{i}-A_{0}}{A}$ which must be equal to $\gamma \sin \sigma t-\varepsilon$ (Col. VII). And, rejecting the average of these values (which is equal to $-\varepsilon$ ), we have the values corresponding to those of $r \sin \sigma t$.

( v ) The final test whether the given data can be represented approximately by the formula in question is dependent on the reducibility of the values listed in Col. VIII into the form $r \sin \sigma t$. The graphical representation of these values listed in Col. VIII (Fig. 1) shows that those are approximately representable by the form $28^{\circ} \sin \sigma t$.

(vi) By the procedure mentioned above, we can determine the four constants $A_{0}, A$, $\gamma$ and $\varepsilon$ of the approximate expression $A_{0}+A \sin (\sigma t-\gamma \sin \sigma t+\varepsilon)$. For this example, $A_{0}=8.9^{\circ} \mathrm{C}, A=2.7^{\circ} \mathrm{C}, \gamma=28^{\circ}$ (about 0.5 radian) and $\varepsilon=228^{\circ}$.

The degree of approximation can be judged by Table 2 which shows the deviation of the computed values from the observed data. In

Table 1. Diurnal variation of air temperature at $1.2 \mathrm{~m}$ height above the ground, Leafield $\left(51^{\circ} 50 \frac{1}{2}^{\prime} \mathrm{N} .1^{\circ} 34 \frac{1}{2}^{\prime} \mathrm{W}\right.$.).

(Annual mean)

\begin{tabular}{|c|c|c|c|c|c|c|c|}
\hline ( I ) & (II) & (III) & (IV) & $(\mathrm{V})$ & $(\mathrm{VI})$ & (VII) & (VIII) \\
\hline $\begin{array}{l}\underset{i}{\text { Hour }} \\
\text { G.M.T. }\end{array}$ & $\theta_{i}$ & $\theta_{i}-A_{0}$ & $\frac{\theta_{i}-A_{0}}{A}$ & $\sin ^{-1} \frac{\theta_{i}-A_{0}}{A}$ & $\sigma t$ & $\sigma t-\sin ^{-1} \frac{\theta_{i}-A_{0}}{A}$ & $\gamma \sin \sigma t$ \\
\hline 0 & $6.9^{\circ} \mathrm{C}$ & $-2.0^{\circ} \mathrm{C}$ & -0.742 & $-132^{\circ} 5^{\prime}$ & $0^{\circ}$ & $132^{\circ} 5^{\prime}$ & $-0^{\circ} 5^{\prime}$ \\
\hline 1 & 6.7 & -2.2 & -0.816 & -12520 & 15 & 14020 & +810 \\
\hline 2 & 6.5 & -2.4 & -0.890 & -11710 & 30 & 14710 & 150 \\
\hline 3 & 6.4 & -2.5 & -0.926 & -11210 & 45 & 15710 & 250 \\
\hline 4 & 6.2 & -2.7 & -1.000 & -900 & 60 & $150 \quad 0$ & 1750 \\
\hline 5 & 6.2 & -2.7 & -1.000 & $\begin{array}{ll}-90 & 0\end{array}$ & 75 & $165 \cdot 0$ & 3250 \\
\hline 6 & 6.5 & -2.4 & -0.890 & -6250 & 90 & 15250 & 2040 \\
\hline 7 & 7.1 & -1.8 & -0.667 & -4150 & 105 & 14650 & 1440 \\
\hline 8 & 7.8 & -1.1 & -0.408 & -245 & 120 & 1445 & 1155 \\
\hline 9 & 8.6 & -0.3 & -0.111 & -620 & 135 & 14120 & 910 \\
\hline 10 & 9.5 & +0.6 & +0.222 & +1250 & 150 & 13710 & 50 \\
\hline 11 & 10.3 & 1.4 & 0.519 & 3115 & 165 & 13345 & +135 \\
\hline 12 & 10.9 & 2.0 & 0.742 & 4755 & 180 & 1325 & -05 \\
\hline 13 & 11.3 & 2.4 & 0.890 & 6250 & 195 & 13210 & $\begin{array}{ll}0 & 0\end{array}$ \\
\hline 14 & 11.6 & 2.7 & 1.000 & $90 \quad 0$ & 210 & $120 \quad 0$ & -1210 \\
\hline 15 & 11.5 & 2.6 & 0.963 & 10540 & 225 & 11920 & -1250 \\
\hline 16 & 11.2 & 2.3 & 0.852 & 12135 & 240 & 11825 & -1345 \\
\hline 17 & 10.6 & 1.7 & 0.630 & 14055 & 255 & $114 \quad 5$ & $-18 \quad 5$ \\
\hline 18 & 9.9 & 1.0 & 0.371 & 15815 & 270 & 11145 & -2025 \\
\hline 19 & 9.1 & +0.2 & +0.074 & $175 \cdot 45$ & 285 & 10915 & -2255 \\
\hline 20 & 8.4 & -0.5 & -0.186 & 19045 & 300 & 10915 & -2255 \\
\hline 21 & 7.9 & -1.0 & -0.371 & 20145 & 315 & 11315 & -1855 \\
\hline 22 & 7.5 & -1.4 & -0.519 & 21115 & 330 & 11845 & -1325 \\
\hline 23 & 7.2 & -1.7 & -0.630 & +2195 & 345 & 12555 & -615 \\
\hline
\end{tabular}


Table 2. Comparison of the computed values with the observed data.

$$
\begin{array}{r}
\theta_{1.2}=8.9+2.7 \sin \left(\sigma t-28^{\circ} \sin \sigma t+228^{\circ}\right) \\
\theta_{30.5}=9.0+2.1 \sin \left(\sigma t-29^{\circ} \sin \sigma t+215^{\circ}\right) \\
\theta_{87.7}=8.9+1.8 \sin \left(\sigma t-29^{\circ} \sin \sigma t+213^{\circ}\right) \\
\quad(t=0 \text { at midnight })
\end{array}
$$

\begin{tabular}{|c|c|c|c|c|c|c|c|c|c|}
\hline \multirow{2}{*}{ Hour } & \multicolumn{3}{|c|}{$1.2 \mathrm{~m}$} & \multicolumn{3}{|c|}{$30.5 \mathrm{~m}$} & \multicolumn{3}{|c|}{$87.7 \mathrm{~m}$} \\
\hline & (1) & $(2)$ & (3) & (1) & (2) & (3) & (1) & (2) & (3) \\
\hline 0 & $6.9^{\circ} \mathrm{C}$ & $6.9^{\circ} \mathrm{C}$ & $0.0^{\circ} \mathrm{C}$ & $7.8^{\circ} \mathrm{C}$ & $7.7^{\circ} \mathrm{C}$ & $0.1^{\circ} \mathrm{C}$ & $7.9^{\circ} \mathrm{C}$ & $7.8^{\circ} \mathrm{C}$ & $0.1^{\circ} \mathrm{C}$ \\
\hline 1. & 6.7 & 6.7 & 0.0 & 7.6 & 7.5 & 0.1 & 7.7 & 7.6 & 0.1 \\
\hline 2 & 6.5 & 6.5 & 0.0 & 7.4 & 7.3 & 0.1 & 7.6 & 7.4 & 0.2 \\
\hline 3 & 6.3 & 6.4 & -0.1 & 7.2 & 7.1 & 0.1 & 7.4 & 7.3 & 0.1 \\
\hline 4 & 6.2 & 6.2 & 0.0 & 7.0 & 7.0 & 0.0 & 7.2 & 7.1 & 0.1 \\
\hline 5 & 6.2 & 6.2 & 0.0 & 6.9 & 6.9 & 0.0 & 7.1 & 7.1 & 0.0 \\
\hline 6 & 6.4 & 6.5 & -0.1 & 6.9 & 6.9 & 0.0 & 7.1 & 7.1 & 0.0 \\
\hline 7 & 6.7 & 7.1 & -0.4 & 7.1 & 7.2 & -0.1 & 7.2 & 7.2 & 0.0 \\
\hline 8 & 7.3 & 7.8 & -0.5 & 7.4 & 7.6 & -0.2 & 7.5 & 7.5 & 0.0 \\
\hline 9 & 8.1. & 8.6 & -0.5 & 7.9 & 8.2 & -0.3 & 7.9 & 8.0 & -0.1 \\
\hline 10 & 9.1 & 9.5 & -0.4 & 8.7 & 8.9 & -0.2 & 8.5 & 8.5 & 0.0 \\
\hline 11 & 10.1 & 10.3 & -0.2 & 9.5 & 9.6 & -0.1 & 9.2 & 9.1 & 0.1 \\
\hline 12 & 10.9 & 10.9 & 0.0 & 10.2 & 10.2 & 0.0 & 9.9 & 9.6 & 0.3 \\
\hline 13 & 11.4 & 11.3 & 0.1 & 10.8 & 10.6 & 0.2 & 10.4 & 10.1 & 0.3 \\
\hline 14 & 11.6 & 11.6 & 0.0 & 11.1 & 11.0 & 0.1 & 10.7 & 10.4 & 0.3 \\
\hline 15 & 11.4 & 11.5 & -0.1 & 11.1 & 11.1 & 0.0 & 10.7 & 10.6 & 0.1 \\
\hline 16 & 10.9 & 11.2 & -0.3 & 10.8 & 11.0 & -0.2 & 10.5 & 10.5 & 0.0 \\
\hline 17 & 10.3 & 10.6 & -0.3 & 10.4 & 10.6 & -0.2 & 10.2 & 10.2 & 0.0 \\
\hline 18 & 9.6 & 9.9 & -0.3 & 9.9 & 10.2 & -0.3 & 9.7 & 9.8 & -0.1 \\
\hline 19 & 8.9 & 9.1 & -0.2 & 9.4 & 9.6 & -0.2 & 9.3 & 9.4 & -0.1 \\
\hline 20 & 8.3 & 8.4 & -0.1 & 9.0 & 9.1 & -0.1 & 9.0 & 8.9 & 0.1 \\
\hline 21 & 7.9 & 7.9 & 0.0 & 8.6 & 8.6 & 0.0 & 8.6 & 8.6 & 0.0 \\
\hline 22 & 7.5 & 7.5 & 0.0 & 8.3 & 8.2 & 0.1 & 8.4 & 8.2 & 0.2 \\
\hline 23 & 7.2 & 7.2 & 0.0 & 8.0 & 7.9 & 0.1 & 8.1 & 8.0 & 0.1 \\
\hline
\end{tabular}

(1) Computed value

(2) Observed value

(2) Deviation

this example, the deviation appears within $\pm 0.5^{\circ} \mathrm{C}$.

Some more examples taken from Johnson's observation at Leafield are treated by the same process, and we get

$$
\begin{array}{r}
\theta=9.0+2.1 \sin \left(\sigma t-29^{\circ} \sin \sigma t+215^{\circ}\right) \\
\text { for } 30.5 \mathrm{~m} \text { height } \\
\theta=8.9+1.8 \sin \left(\sigma t-29^{\circ} \sin \sigma t+213^{\circ}\right) \\
\text { for } 87.7 \mathrm{~m} \text { height. }
\end{array}
$$

The test (v) mentioned above and the comparison with the observed data are shown in Fig. 1 and Table 2 respectively.

The temperature variations at different le- vels for every season are also treated, and the results are summarized in Table 3 . The graphs of the test (v) are appended in Fig. 2.

\section{§3. Physical and Meteorological Remarks}

(a) It is clear that the ideal expression which represents the diurnal variation of air temperature is a periodic function with a single period of a day, that is, $\theta=f(t)=f(t+T)$ where $T=24$ hours. However, it is very difficult to find the functional form which represents rigorously the observed data, or to derive it theoretically.

There is no reason that the periodic part 
Table 3. Four constants for the temperature variations at Leafield.

$\theta=A_{0}+A \sin (\sigma t-\gamma \sin \sigma t+\varepsilon) \quad(t=0$ at midnight $)$

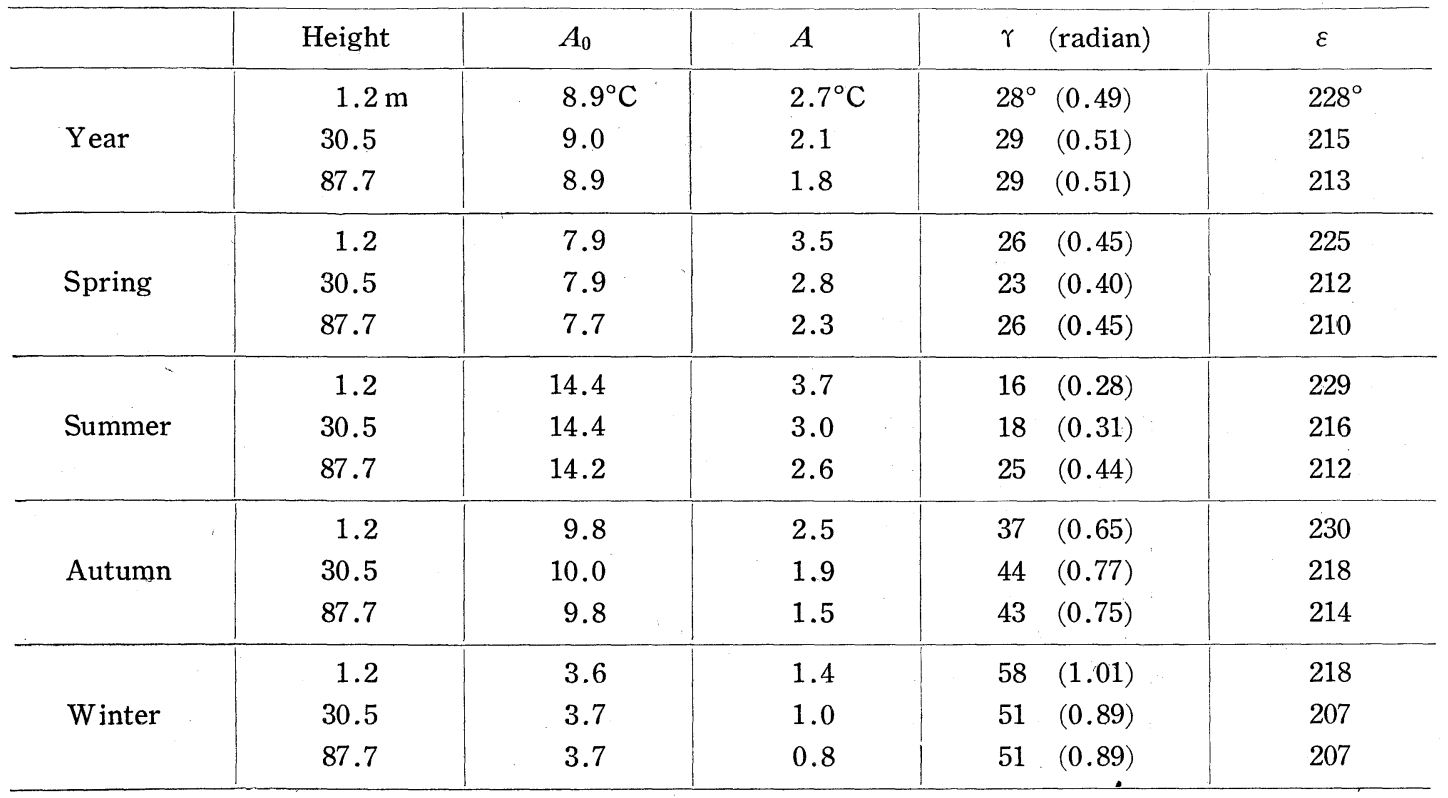
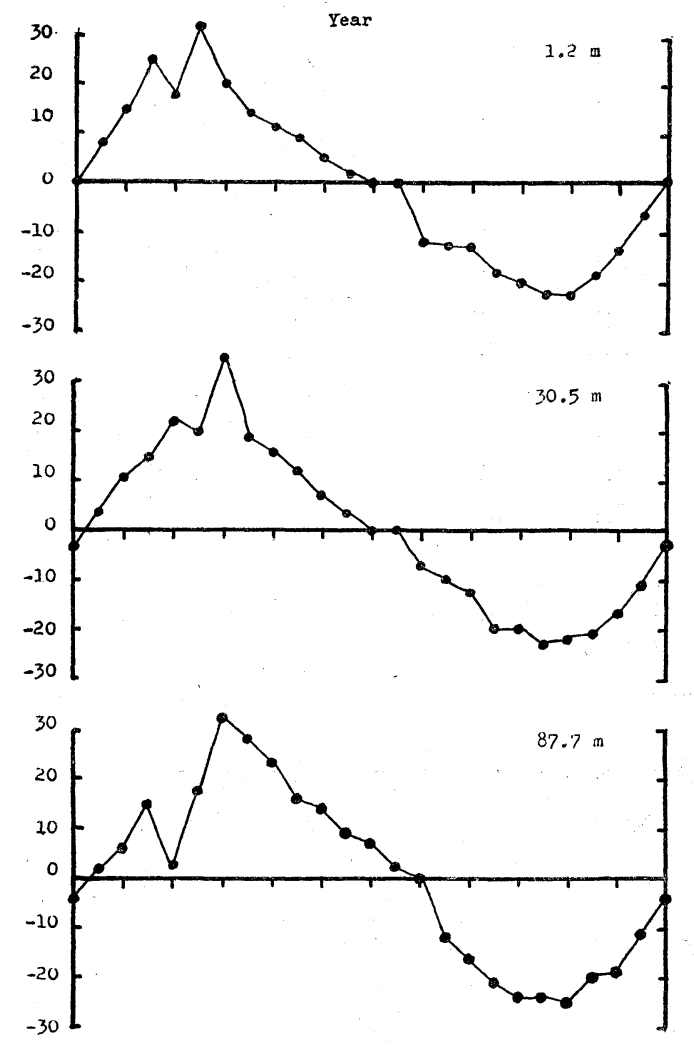

$\begin{array}{lllllllllllll}1 & 1 & 1 & 1 & 1 & 1 & 1 & 1 & 1 & 1 & 1 & 1 & 1 \\ 0 & 2 & 4 & 6 & 8 & 10 & 12 & 14 & 16 & 18 & 20 & 22 & 24\end{array}$

Fig. 1. can be represented by a simplest form of periodic function, i.e., $\boldsymbol{r} \sin (\sigma t+\delta)$. In fact, the temperature variation is mainly governed by the receiving solar radiation during the daytime and the emission of terrestrial radiation throughout day and night at the ground surface. And, if we consider a model suggested by D. Brunt [2] that

$$
\begin{array}{rlr}
R a(t)=-I \sin \sigma t-R_{N} & \text { for } \quad-\pi<\sigma t<0 \\
=\quad-R_{N} & \text { for } \quad 0<\sigma t<\pi \\
& & (t=0 \text { at sunset })
\end{array}
$$

and

$$
\int_{-\pi / \sigma}^{+\pi / \sigma} R a(t) d t=0
$$

which is expressed by the form of a Fourier series

$$
\begin{aligned}
R a(t)= & -\frac{1}{2} I \sin \sigma t \\
& -\frac{2}{\pi} I\left\{\frac{1}{3} \cos 2 \sigma t+\frac{1}{15} \cos 4 \sigma t+\cdots\right. \\
& \left.+\frac{1}{n^{2}-1} \cos n \sigma t+\cdots\right\} \\
& (n, \text { even integer }), \quad(4)
\end{aligned}
$$

then we see the appearance of the higher harmonic terms on the controlling agency of the diurnal temperature variation. However, 

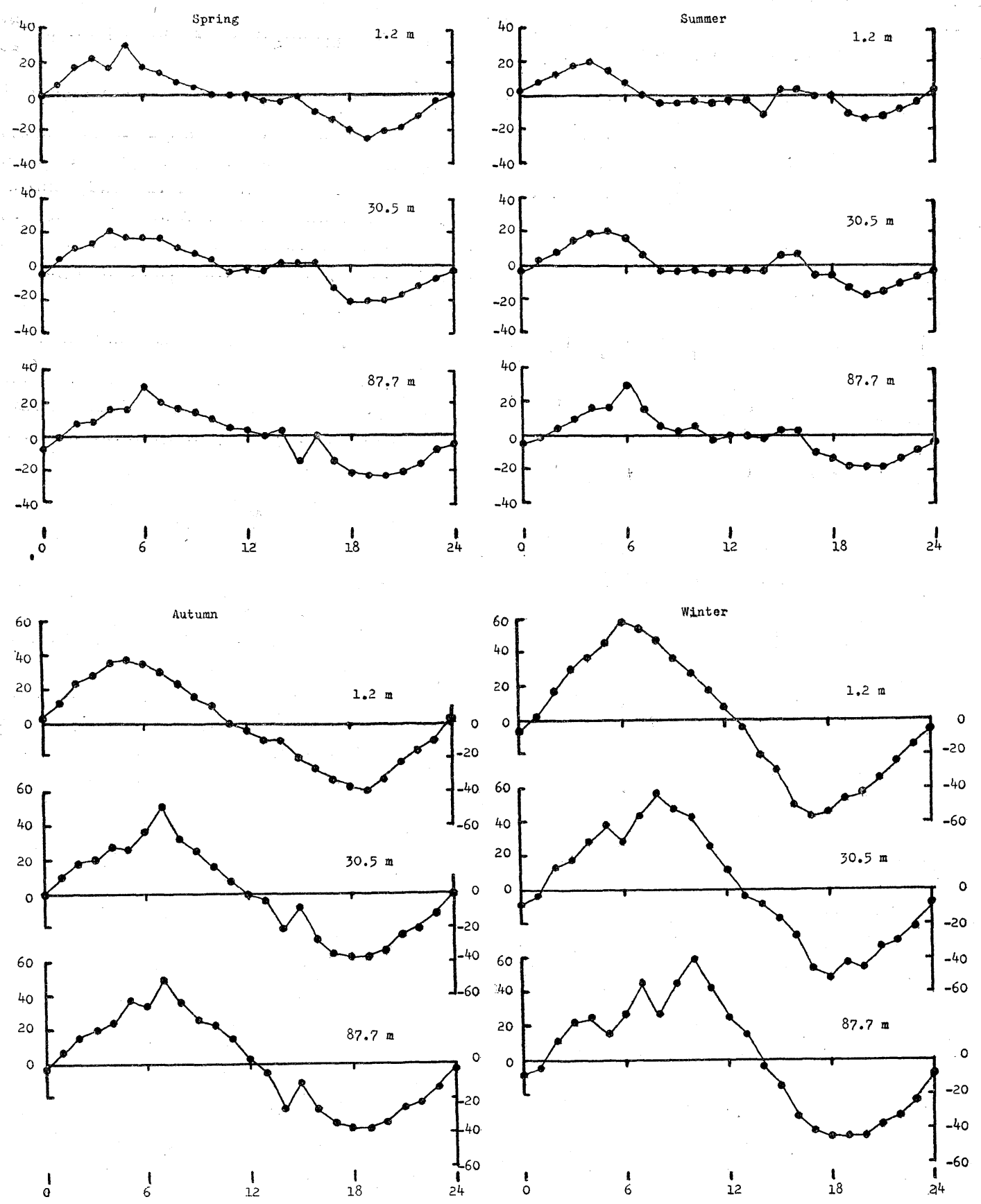

Fig. 2. 
it must be borne in mind that appearance of the semi-diurnal and other harmonic shorter periods is merely mathematical and has no physical reality.

Moreover, if we assume that the heat transfer is governed by the eddy diffusion equation $\frac{\partial \theta}{\partial t}=\kappa \frac{\partial^{2} \theta}{\partial z^{2}} \quad(\kappa=$ const. $)$ in the air layer and by the conduction equation $\frac{\partial \theta_{B}}{\partial t}=\kappa_{B} \frac{\partial^{2} \theta_{B}}{\partial z^{2}}\left(\kappa_{B}=\right.$ const.) through the ground, we have a solution for the air layer

$$
\begin{aligned}
& \theta=\bar{\theta}+\frac{2 I}{\pi\left(\sqrt{\kappa} \rho c+\sqrt{\left.\kappa_{B} \rho_{B} c_{B}\right)} \sqrt{\sigma}\right.} \\
& \times\left\{\frac{\pi}{4} \quad e^{-} \sqrt{\frac{\sigma}{2 \kappa} z} \sin \left(\sigma t-\sqrt{\frac{\sigma}{2 \kappa}} z+\frac{5}{4} \pi\right)\right. \\
& +\frac{1}{3 \sqrt{2}} e^{-} \sqrt{\frac{\sigma}{\kappa} z} \sin \left(2 \sigma t-\sqrt{\frac{\sigma}{\kappa}} z+\frac{1}{4} \pi\right) . \\
& +\frac{1}{30} \quad e^{-} \sqrt{\frac{2 \sigma}{\kappa} z} \sin \left(4 \sigma t-\sqrt{\frac{2 \sigma}{\kappa}} z+\frac{5}{4} \pi\right) \\
& +\cdots \ldots \ldots \ldots \\
& +\frac{(-1)^{\frac{n}{2}+1}}{\left(n^{2}-1\right) \sqrt{n}} e^{-} \sqrt{2 \kappa}^{\bar{n} \bar{z}} \sin \left(n \sigma t-\sqrt{\frac{n \sigma}{2 \kappa}} z+\frac{1}{4} \pi\right) \\
& +\cdots \cdots \cdots \cdots\}
\end{aligned}
$$

( $t=0$ at mid night; $n$, even integer) which satisfies the conditions

$$
\left.\theta\right|_{z=0}=\left.\theta_{B}\right|_{z=0} \quad \underset{z \rightarrow \infty}{\theta=\bar{\theta}}, \quad \theta_{B \rightarrow-\infty}=\bar{\theta}_{B}
$$

and

$$
R a(t)=-\left.\kappa \rho c \frac{\partial \theta}{\partial z}\right|_{z=0}+\left.\kappa_{B} \rho_{B} c_{B} \frac{\partial \theta_{B}}{\partial z}\right|_{z=0} .
$$

Then, the amplitude ratios of the semi-diurnal and higher harmonic terms to the diurnal one are, at the ground surface,

$$
\begin{aligned}
& \frac{r_{2}}{r_{1}}=\frac{2 \sqrt{2}}{3 \pi}=0.30, \quad \frac{r_{3}}{r_{1}}=0, \quad \frac{r_{4}}{r_{1}}=\frac{2}{15 \pi}=0.04, \\
& \cdots \ldots \ldots \ldots, \quad \frac{r_{n}}{r_{1}}=\frac{4}{\left(n^{2}-1\right) \sqrt{n \pi}} .
\end{aligned}
$$

This result shows that the diurnal temperature variation can be approximately expressed by the diurnal and semi-diurnal terms, neglecting the higher harmonic terms.

Referring the result of the discussion by a model, we can generally speak that the observed temperature variation may be approxi- mately expressed by the diurnal and semidiurnal terms only. In fact, the results of actual analysis of the diurnal variations verify this conclusion.

(b) The assumption of the equation $\frac{\partial \theta}{\partial t}$ $=\kappa \frac{\partial^{2} \theta}{\partial z^{2}}$ which governs the heat transfer in the air layer must be modified from various points of view. We may suppose that the existing diurnal variation of the eddy diffusi$\operatorname{vity}(\kappa)$ may have much influence upon the temperature variation itself. In fact, $\boldsymbol{\kappa}$ is larger during the daytime than at night. If we take

$$
\kappa=\kappa_{0}(1-\gamma \cos \sigma t) \quad(t=0 \text { at midnight })
$$

as a simple model which contains the idea mentioned above, we have a periodic solution of the eddy diffusion equation in the following form

$$
\begin{aligned}
\theta=\bar{\theta} & +\sum_{n=1}^{\infty} R_{n} e^{-} \sqrt{\frac{n \sigma}{2 \kappa_{0}} z} \sin \{n(\sigma t-\gamma \sin \sigma t) \\
& \left.-\sqrt{\frac{n \sigma}{2 \kappa_{0}}} z+\varepsilon_{n}\right\} .
\end{aligned}
$$

The functional form of author's new expression is suggested by the above expression.

Any expression given in the form of the ordinary Fourier series can be rearranged into the new series by the aid of the following relations. If we express in our series

$$
\begin{aligned}
\theta=A_{0} & +R_{1} \sin \left(x+\varepsilon_{1}\right)+R_{2} \sin \left(2 x+\varepsilon_{2}\right)+\cdots \\
=A_{0} & +A_{1} \cos x+A_{2} \cos 2 x+\cdots \\
& +B_{1} \sin x+B_{2} \sin 2 x+\cdots
\end{aligned}
$$

where

$$
x=\sigma t-\gamma \sin \sigma t,
$$

and in the ordinary Fourier series

$$
\begin{aligned}
\theta=a_{0} & +r_{1} \sin \left(\sigma t+\delta_{1}\right)+r_{2} \sin \left(2 \sigma t+\delta_{2}\right) \\
& +r_{3} \sin \left(3 \sigma t+\delta_{3}\right)+\cdots \\
=a_{0} & +a_{1} \cos \sigma t+a_{2} \cos 2 \sigma t+a_{3} \cos 3 \sigma t+\cdots \\
& +b_{1} \sin \sigma t+b_{2} \sin 2 \sigma t+b_{3} \sin 3 \sigma t+\cdots,(10)
\end{aligned}
$$

then we have the relations

$$
\begin{aligned}
& A_{0}=a_{0}-\frac{\gamma}{2} a_{1} \\
& \begin{array}{c}
A_{1}=\quad a_{1}\left\{J_{0}(\gamma)-J_{2}(\gamma)\right\}+2 a_{2}\left\{J_{-1}(\gamma)-J_{3}(\gamma)\right\} \\
\quad+3 a_{3}\left\{J_{-2}(\gamma)-J_{4}(\gamma)\right\} \cdots
\end{array}
\end{aligned}
$$




$$
\begin{aligned}
& B_{1}=b_{1}\left\{J_{0}(\gamma)+J_{2}(\gamma)\right\}+2 b_{2}\left\{J_{-1}(\gamma)+J_{3}(\gamma)\right\} \\
& +3 b_{3}\left\{J_{-2}(\gamma)+J_{4}(\gamma)\right\} \cdots \\
& A_{2}=\frac{1}{2}\left[a_{1}\left\{J_{1}(2 \gamma)-J_{3}(2 \gamma)\right\}+2 a_{2}\left\{J_{0}(2 \gamma)-J_{4}(2 \gamma)\right\}\right. \\
& \left.+3 a_{3}\left\{J_{-1}(2 \gamma)-J_{5}(2 \gamma)\right\}+\cdots\right] \\
& B_{2}=\frac{1}{2}\left[b_{1}\left\{J_{1}(2 \gamma)+J_{3}(2 \gamma)\right\}+2 b_{2}\left\{J_{0}(2 \gamma)+J_{4}(2 \gamma)\right\}\right. \\
& \left.+3 b_{3}\left\{J_{-1}(2 \gamma)+J_{5}(2 \gamma)\right\}+\cdots\right]
\end{aligned}
$$

by the aid of the mathematical relations

$$
\begin{aligned}
& \cos m \sigma t=p_{0}+p_{1} \cos x+p_{2} \cos 2 x+\cdots \\
& +p_{n} \cos n x+\cdots \\
& \sin m \sigma t=\quad q_{1} \sin x+q_{2} \sin 2 x+\cdots \\
& +q_{n} \sin n x+\cdots
\end{aligned}
$$

where

$$
\begin{aligned}
& p_{0}=\left\{\begin{array}{cc}
-\frac{\gamma}{2} & m=1 \\
0 & m \neq 1
\end{array}\right. \\
& p_{n}=\frac{m}{n}\left\{J_{n-m}(n \gamma)-J_{n+m}(n \gamma)\right\} \\
& q_{n}=\frac{m}{n}\left\{J_{n-m}(n \gamma)+J_{n+m}(n \gamma)\right\}
\end{aligned}
$$

and $J_{N}(x)$ indicates the Bessel function of $N$ th order with argument, $x$. Accordingly, if we can specify the value of $\gamma$, the variations ex- pressed by the ordinary Fourier series (10) can be rearranged into our new series (9).

Johnson's observations are treated along the above line, and the results by giving $\gamma=0.5$ (radian) are shown in Table 4 . This table shows that the ratio $R_{2} / R_{1}$ is reduced to less than $0 \cdot 1$ without exception. Accordingly, we can suppose that almost all of the variations in question may be expressed approximately by the diurnal term only, that is, $R_{1} \sin (\sigma t$ $\left.-r \sin \sigma t+\varepsilon_{1}\right)$. On the other hand, the amplitude of the semi-diurnal term of the ordinary Fourier series $\left(\boldsymbol{r}_{2}\right)$ is rather great and the ratio $r_{2} / r_{1}$ is nearly 0.2 and hence can not be neglected even in the sense of approximation. The accuracy of approximation of the expression $a_{0}+r_{1} \sin \left(\sigma t+\delta_{1}\right)+r_{2} \sin \left(2 \sigma t+\delta_{2}\right)$ may be better to a certain extent than that of the expression $A_{0}+R_{1} \sin \left(\sigma t-\gamma \sin \sigma t+\varepsilon_{1}\right)$. But,

\begin{tabular}{|c|c|c|c|}
\hline$a_{0}=$ & $8.57^{\circ} \mathrm{C}$ & & \\
\hline \multicolumn{2}{|c|}{$a_{1}=-2.04$} & $r_{1}=2.60^{\circ} \mathrm{C}$ & \multirow{4}{*}{$\frac{r_{2}}{r_{1}}=0.19$} \\
\hline \multicolumn{2}{|c|}{$b_{1}=-1.62$} & $\delta_{1}=231^{\circ} 35^{\prime}$ & \\
\hline$a_{2}=$ & 0.35 & $r_{2}=0.49^{\circ} \mathrm{C}$ & \\
\hline$b_{2}=$ & 0.34 & $\delta_{2}=46^{\circ} 10^{\prime}$ & \\
\hline$a_{3}=$ & 0.07 & $r_{3}=0.07^{\circ} \mathrm{C}$ & $r_{3}$ \\
\hline$b_{3}=$ & 0.04 & $\delta_{3}=61^{\circ} 45^{\prime}$ & $\overline{r_{1}}$ \\
\hline
\end{tabular}
it must be remembered that the former expression involves five constants, while the latter is defined by four constants and yet does not contain the semi-diurnal term which has no physical significance. Therefore, the

\begin{tabular}{|c|c|c|c|}
\hline$a_{0}=$ & $8.74^{\circ} \mathrm{C}$ & & \\
\hline \multicolumn{2}{|c|}{$a_{1}=-1.26$} & $r_{1}=2.02^{\circ} \mathrm{C}$ & \multirow{4}{*}{$\frac{r_{2}}{r_{1}}=0.19$} \\
\hline \multicolumn{2}{|c|}{$b_{1}=-1.58$} & $\delta_{1}=218^{\circ} 25^{\prime}$ & \\
\hline$a_{2}=$ & 0.18 & $r_{2}=0.39^{\circ} \mathrm{C}$ & \\
\hline$b_{2}=$ & 0.35 & $\delta_{2}=27^{\circ} 50^{\prime}$ & \\
\hline$a_{3}=$ & 0.02 & $r_{3}=0.03^{\circ} \mathrm{C}$ & \\
\hline$b_{3}=$ & 0.03 & $\delta_{3}=36^{\circ} 55^{\prime}$ & \\
\hline
\end{tabular}
latter expression seems to be better than the former if the accuracy of the latter is the same order or even when it is dropping in small degree.

Table 4. Diurnal variation of air temperature at heights $1.2 \mathrm{~m}$ and $30.5 \mathrm{~m}$, (annual mean), Leafield.

(1) $1.2 \mathrm{~m}$ height.

Harmonic constants.

Constants of the series (9).

\begin{tabular}{|c|c|}
\hline$A_{0}=9.08^{\circ} \mathrm{C}$ & \\
\hline$A_{1}=-2.01$ & $R_{1}=2.66^{\circ} \mathrm{C}$ \\
$B_{1}=-1.73$ & $\varepsilon_{1}=229^{\circ} 15^{\prime}$ \\
\hline$A_{2}=-0.20$ & $R_{2}=0.24^{\circ} \mathrm{C}$ \\
$B_{2}=-0.13$ & $\varepsilon_{2}=237^{\circ} 5^{\prime}$ \\
\hline
\end{tabular}

(2) $30.5 \mathrm{~m}$ height.

Harmonic constants.

Constants of the series (9).

\begin{tabular}{|c|c|}
\hline$A_{0}=9.06^{\circ} \mathrm{C}$ & \\
\hline$A_{1}=-1.24$ & $R_{1}=2.10^{\circ} \mathrm{C}$ \\
$B_{1}=-1.70$ & $\varepsilon_{1}=216^{\circ} 10^{\prime}$ \\
\hline$A_{2}=-0.15$ & $R_{2}=0.19^{\circ} \mathrm{C}$ \\
$B_{2}=-0.12$ & $\varepsilon_{2}=231^{\circ} 20^{\prime}$ \\
\hline
\end{tabular}


A theoretical discussion to illustrate the smallness of the ratio $R_{2} / R_{1}$ can be done along the same line as mentioned previously. But, it is very troublesome and the rigorous solution can not be easily found. Omitting to write this discussion, the following note is added to supply our purpose.

Assuming that the theoretical expression obtained by putting $z=0$ in the solution (5), namely,

$$
\begin{aligned}
\theta=\bar{\theta} & +I^{\prime}\left\{\frac{\pi}{4} \sin \left(\sigma t+\frac{5}{4} \pi\right)\right. \\
& +\frac{1}{3 \sqrt{2}} \sin \left(2 \sigma t+\frac{1}{4} \pi\right) \\
& \left.+\frac{1}{30} \sin \left(4 \sigma t+\frac{5}{4} \pi\right)+\cdots\right\}
\end{aligned}
$$

represents roughly the temperature variation in question, and transforming into our series, we have, putting $r=0.5$,

$$
\begin{aligned}
\theta=\bar{\theta}+0.439 I^{\prime} & +0.850 I^{\prime} \sin \left(\sigma t-28^{\circ} \sin \sigma t+223^{\circ}\right) \\
& +0.007 I^{\prime} \sin \left(2 \sigma t-56^{\circ} \sin \sigma t+129^{\circ}\right) \\
& +\cdots \cdots \cdots
\end{aligned}
$$

Then, $R_{2} / R_{1}=0.008$, which is the negligible order compared with unity. Consequently, we may suppose that almost all of the variations in qustion can be represented approximately by the new expression $A_{0}+A \sin (\sigma t$ $-\gamma \sin \sigma t+\varepsilon)$ with sufficient accuracy.

\section{§4. Application to Climatology}

The new expression which the writer proposed can be utilized for the shorter description to define the diurnal temperature variations at the localities.

When the hourly data or bi-hourly data of these variations are given, the four constants which define these variations can be found by the method written in $\S 2$. These constants are listed in Tables 5 and 6 , which give the values for 11 selected Japanese stations including a Formosan one and for the worldwide 15 selected observatories and other special regions. The author wants such list to be added in the climatological table.

When we know the maximum and minimum values $(M$ and $m$ ) and their occurring times $\left(t_{M}\right.$ and $\left.t_{m}\right)$, we can also find the four constants, by the aid of the relations

$$
A_{0}=\frac{M+m}{2}, \quad A=\frac{M-m}{2}
$$

and by solving the simultaneous equations

$$
\left.\begin{array}{l}
\sigma t_{M}-r \sin \sigma t_{M}+\varepsilon=90^{\circ} \\
\sigma t_{m}-r \sin \sigma t_{m}+\varepsilon=-90^{\circ}
\end{array}\right\} .
$$

Inspecting the listed values of $\gamma$ in Tables 3,5 and 6 , we see:

(i) $\gamma$ appears to be roughly independent of height, but varies from about $20^{\circ}$ in summer to about $55^{\circ}$ in winter at Leafield (Table $3)$.

(ii) For Japanese stations (Table 5), $\gamma$ lies between $31^{\circ}$ and $46^{\circ}$ for the year, $45^{\circ}$ and $65^{\circ}$ for January and $25^{\circ}$ and $41^{\circ}$ for July. A marked seasonal variation, larger in winter and smaller in summer, can be found at every station.

(iii) Similar remarkable seasonal variation can be found at almost all observatories in the world (Table 6), despite of being less remarkable in the equatorial region (for example, Batavia).

(iv) It appears that $\gamma$ decreases generally with latitude, ranging from $21^{\circ}$ for high latitude to $40^{\circ}$ for low latitude for the annual mean, but the very small value of $\gamma$ is seen in the polar regions.

( v ) $\gamma$ is larger at high lever stations than at low levels without exception in the present three examples.

If we consider physically, $\gamma$ means the relative amplitude of the diurnal variation of the eddy diffusivity, that is, $\kappa=\kappa_{0}(1-\gamma \cos \sigma t)$. Accordingly, the value of $\gamma$ greater than 1 radian (about $57^{\circ}$ ) gives a negative of $\kappa$ which has no physical reality. In fact, there is no reason that the actual change of $\kappa$ undergoes such simple model as above. And, remembering that the observed temperature variation is empirically representable in the form $A_{0}+A \sin (\sigma t-\gamma \sin \sigma t+\varepsilon)$, we may suppose that $\gamma$, even when it exceeds 1 radian, plays the role of an index which shows the diurnal variation of eddy diffusivity or an index of the diurnal changeability of atmospheric stirring at the locality. Therefore, adding the values of $\gamma$ to define the diurnal variation will bring some advantages for the specification of the climatic state from the point of view mentioned above. 
Table 5. Four constants for the temperature variations at 11 selected Japanese stations.

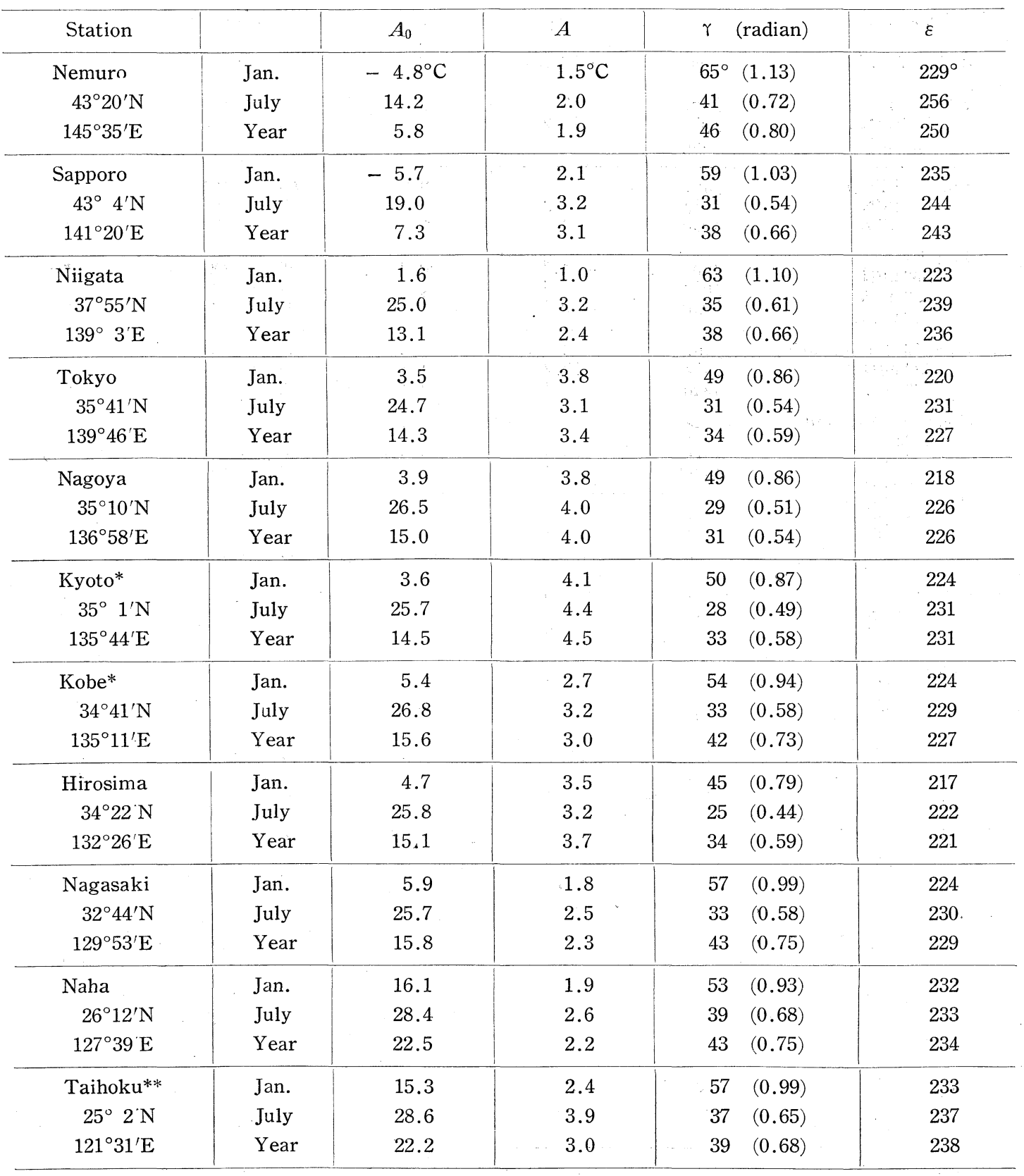

** Station in Formosa.

Data were taken from Reference [3], except two marked with asterisk *.

It must be noticed that $A_{0}$ in the new expression is not the daily mean temperature $\left(a_{0}\right)$, but the average of the maximum and minimum temperatures $(M+m / 2)$. From the relations (11), we have

$$
\begin{aligned}
A_{0} & =a_{0}-\frac{\gamma}{2} a_{1} \\
& =a_{0}-\frac{\gamma}{2} r_{1} \cdot \sin \delta_{1}
\end{aligned}
$$

where $r_{1}$ and $\delta_{1}$ are the amplitude and phase 
Table 6. Four constants for the temperature variations at a few observatories in the world.

\begin{tabular}{|c|c|c|c|c|c|}
\hline Observatory & & $A_{0}$ & $A$ & $\gamma \quad$ (radian) & $\varepsilon$ \\
\hline in the Arctic & Year & $-19.2^{\circ} \mathrm{C}$ & $0.3^{\circ} \mathrm{C}$ & $7^{\circ}(0.12)$ & $239^{\circ}$ \\
\hline $\begin{array}{l}\text { Aberdeen } \\
57^{\circ} 10^{\prime} \mathrm{N} \\
2^{\circ} 6^{\prime} \mathrm{W}\end{array}$ & $\begin{array}{l}\text { Jan. } \\
\text { July } \\
\text { Year }\end{array}$ & $\begin{array}{r}3.7 \\
13.2 \\
7.9\end{array}$ & $\begin{array}{l}0.8 \\
2.0 \\
1.5\end{array}$ & $\begin{array}{ll}51 & (0.89) \\
25 & (0.44) \\
25 & (0.44)\end{array}$ & $\begin{array}{l}221 \\
234 \\
231\end{array}$ \\
\hline $\begin{array}{c}\text { Fort William } \\
56^{\circ} 48^{\prime} \mathrm{N} \\
5^{\circ} 5^{\prime} \mathrm{W}\end{array}$ & $\begin{array}{l}\text { Jan. } \\
\text { July } \\
\text { Year }\end{array}$ & $\begin{array}{r}3.9 \\
14.0 \\
8.5\end{array}$ & $\begin{array}{l}0.5 \\
2.4 \\
1.7\end{array}$ & $\begin{aligned} 66 & (1.15) \\
3 & (0.05) \\
21 & (0.37)\end{aligned}$ & $\begin{array}{l}213 \\
220 \\
220\end{array}$ \\
\hline $\begin{array}{c}\text { Ben Nevis } \\
56^{\circ} 48^{\prime} \mathrm{N} \\
5^{\circ} 0^{\prime} \mathrm{W} \\
(1343 \mathrm{~m}) \\
\end{array}$ & $\begin{array}{l}\text { Jan. } \\
\text { July } \\
\text { Year }\end{array}$ & $\begin{array}{r}-4.7 \\
5.4 \\
-0.1 \\
\end{array}$ & $\begin{array}{l}0.2 \\
1.1 \\
0.7\end{array}$ & $\begin{array}{ll}85 & (1.48) \\
14 & (0.24) \\
31 & (0.54)\end{array}$ & $\begin{array}{l}229 \\
221 \\
226 \\
\end{array}$ \\
\hline $\begin{array}{c}\text { Parc St Maur(Paris) } \\
48^{\circ} 49^{\prime} \mathrm{N} \\
2^{\circ} 29^{\prime} \mathrm{E}\end{array}$ & $\begin{array}{l}\text { Jan. } \\
\text { July } \\
\text { Year }\end{array}$ & $\begin{array}{r}2.7 \\
18.2 \\
10.4\end{array}$ & $\begin{array}{l}1.6 \\
4.6 \\
3.4\end{array}$ & $\begin{array}{ll}57 & (0.99) \\
16 & (0.28) \\
22 & (0.38)\end{array}$ & $\begin{array}{l}215 \\
228 \\
227\end{array}$ \\
\hline $\begin{array}{c}\text { Clermont Ferrand } \\
45^{\circ} 46^{\prime} \mathrm{N} \\
3^{\circ} 5^{\prime} \mathrm{E} \\
(388 \mathrm{~m})\end{array}$ & $\begin{array}{l}\text { Jan. } \\
\text { July } \\
\text { Year }\end{array}$ & $\begin{array}{r}2.2 \\
18.4 \\
10.4\end{array}$ & $\begin{array}{l}2.7 \\
5.6 \\
4.4 \\
\end{array}$ & $\begin{array}{ll}58 & (1.01) \\
18 & (0.31) \\
23 & (0.40) \\
\end{array}$ & $\begin{array}{l}223 \\
231 \\
231 \\
\end{array}$ \\
\hline $\begin{array}{c}\text { Puy de Dome } \\
45^{\circ} 46^{\prime} \mathrm{N} \\
2^{\circ} 58^{\prime} \mathrm{E} \\
(1467 \mathrm{~m}) \\
\end{array}$ & $\begin{array}{l}\text { Jan. } \\
\text { July } \\
\text { Year }\end{array}$ & $\begin{array}{r}-2.6 \\
11.2 \\
3.8\end{array}$ & $\begin{array}{l}0.4 \\
1.6 \\
1.0\end{array}$ & $\begin{array}{ll}75 & (1.31) \\
23 & (0.40) \\
35 & (0.61)\end{array}$ & $\begin{array}{l}208 \\
213 \\
216\end{array}$ \\
\hline $\begin{array}{l}\text { Tiflis* } \\
41^{\circ} 43^{\prime} \mathrm{N} \\
\quad 44^{\circ} 48^{\prime} \mathrm{E}\end{array}$ & $\begin{array}{l}\text { Dec-Feb. } \\
\text { June-Aug. }\end{array}$ & $\begin{array}{r}3.9 \\
22.2\end{array}$ & $\begin{array}{l}3.4 \\
4.7\end{array}$ & $\begin{array}{ll}46 & (0.80) \\
20 & (0.35)\end{array}$ & $\begin{array}{l}213 \\
220\end{array}$ \\
\hline $\begin{array}{l}\text { Lahore } \\
31^{\circ} 34^{\prime} \mathrm{N} \\
74^{\circ} 20^{\prime} \mathrm{E} \\
(214 \mathrm{~m}) \\
\end{array}$ & $\begin{array}{l}\text { Jan. } \\
\text { July } \\
\text { Year }\end{array}$ & $\begin{array}{l}13.4 \\
32.3 \\
24.5\end{array}$ & $\begin{array}{l}6.2 \\
3.8 \\
6.1\end{array}$ & $\begin{array}{ll}41 & (0.72) \\
31 & (0.54) \\
35 & (0.61)\end{array}$ & $\begin{array}{l}221 \\
221 \\
222 \\
\end{array}$ \\
\hline $\begin{array}{l}\text { Leh } \\
\begin{array}{l}34^{\circ} 10^{\prime} \mathrm{N} \\
77^{\circ} 42^{\prime} \mathrm{E} \\
(3506 \mathrm{~m})\end{array}\end{array}$ & $\begin{array}{l}\text { Jan. } \\
\text { July } \\
\text { Year }\end{array}$ & $\begin{array}{r}-7.0 \\
17.4 \\
5.5\end{array}$ & $\begin{array}{l}4.9 \\
6.0 \\
5.8\end{array}$ & $\begin{array}{ll}42 & (0.73) \\
35 & (0.61) \\
38 & (0.66)\end{array}$ & $\begin{array}{l}223 \\
222 \\
224\end{array}$ \\
\hline $\begin{array}{l}\text { Calcutta } \\
22^{\circ} 32^{\prime} \mathrm{N} \\
88^{\circ} 20^{\prime} \mathrm{E}\end{array}$ & $\begin{array}{l}\text { Jan. } \\
\text { July } \\
\text { Year }\end{array}$ & $\begin{array}{l}19.1 \\
28.5 \\
25.8\end{array}$ & $\begin{array}{l}4.7 \\
1.6 \\
3.2\end{array}$ & $\begin{array}{ll}46 & (0.80) \\
41 & (0.72) \\
40 & (0.70)\end{array}$ & $\begin{array}{l}216 \\
235 \\
224\end{array}$ \\
\hline $\begin{array}{c}\text { San José } \\
\text { de Costarica } \\
10^{\circ} 0^{\prime} \mathrm{N} \\
84^{\circ} 20^{\prime} \mathrm{W} \\
\end{array}$ & $\begin{array}{l}\text { Jan., Feb. } \\
\text { Sept., Oct. }\end{array}$ & $\begin{array}{l}19.8 \\
20.7\end{array}$ & $\begin{array}{l}4.6 \\
3.7\end{array}$ & $\begin{array}{ll}47 & (0.82) \\
60 & (1.05)\end{array}$ & $\begin{array}{l}233 \\
248 \\
\end{array}$ \\
\hline $\begin{array}{l}\text { Batavia } \\
6^{\circ} 11^{\prime} \mathrm{S} \\
106^{\circ} 50^{\prime} \mathrm{E}\end{array}$ & $\begin{array}{l}\text { Jan. } \\
\text { July } \\
\text { Year }\end{array}$ & $\begin{array}{l}25.7 \\
26.1 \\
26.3\end{array}$ & $\begin{array}{l}2.3 \\
3.4 \\
3.0\end{array}$ & $\begin{array}{ll}36 & (0.63) \\
37 & (0.65) \\
38 & (0.66)\end{array}$ & $\begin{array}{l}225 \\
221 \\
226\end{array}$ \\
\hline $\begin{array}{c}\text { Cape of Good Hope } \\
33^{\circ} 56^{\prime} \mathrm{S} \\
18^{\circ} 29^{\prime} \mathrm{E}\end{array}$ & $\begin{array}{l}\text { Jan. } \\
\text { July } \\
\text { Year }\end{array}$ & $\begin{array}{l}20.1 \\
12.7 \\
16.3\end{array}$ & $\begin{array}{l}2.9 \\
2.5 \\
2.7\end{array}$ & $\begin{array}{ll}37 & (0.65) \\
50 & (0.87) \\
36 & (0.63)\end{array}$ & $\begin{array}{l}238 \\
220 \\
232\end{array}$ \\
\hline $\begin{array}{r}\text { Melbourne* } \\
37^{\circ} 50^{\prime} \mathrm{S} \\
144^{\circ} 59^{\prime} \mathrm{E}\end{array}$ & Year & 15.2 & 4.0 & $30 \quad(0.52)$ & 245 \\
\hline $\begin{array}{c}\text { Hut Point } \\
\text { Cape Evans } \\
77^{\circ} 30^{\prime} \mathrm{S} \\
167^{\circ} \quad \mathrm{E} \\
\end{array}$ & Year & -18.0 & 0.5 & $9 \quad(0.16)$ & 230 \\
\hline $\begin{array}{l}\text { Atlantic* } \\
\text { Ocean } \\
122_{2}^{\circ} \mathrm{N}-4^{\circ} \mathrm{S}\end{array}$ & & 26.4 & 0.5 & $27 \quad(0.47)$ & 232 \\
\hline
\end{tabular}

Data were taken from Reference [4], with exception of some marked with asterisk * and taken from References [5] and [6]. 
angle of the diurnal harmonic term of the temperature variation. If we allow the rough approximation that $r_{1} \approx A$ where $A$ is the periodic daily amplitude $(M-m / 2)$ and that $\delta_{1} \approx 225^{\circ}$ for all of these variations, we have a practical rough formula

$$
A_{0} \approx a_{0}+s A
$$

where $s$ is a constant which varies with $\gamma$. This practical formula is tested by the data of selected Japanese stations and we have the following values for a constant $s$.

$\begin{array}{ccc}\text { Season } & \text { Mean } & \text { Range } \\ \text { Year } & 0.14 & 0.08-0.21 \\ \text { Jan. } & 0.18 & 0.13-0.28 \\ \text { July } & 0.07 & 0.00-0.20\end{array}$

Moreover, if we allow a further approximation that $A \approx A^{\prime}$ where $A^{\prime}$ is the nonperiodic daily amplitude derived from the daily observation of the maximum and minimum thermometers, then we have a practical formula

$$
A_{0} \approx a_{0}+s A^{\prime} .
$$

However, $A^{\prime} \geqslant A$, therefore a smaller value of $s$ may be expected. This relation shows that the difference between the daily mean temperature $\left(a_{0}\right)$ and the average of the maximum and minimum temperatures $\left(A_{0}\right)$ is roughly proportional to the daily temperature range.

\section{§5. Summary}

(i) The diurnal variation of air tempera- ture can be expressed by the new approximate form $A_{0}+A \sin (\sigma t-\gamma \sin \sigma t+\varepsilon)$ with sufficient accuracy.

(ii) A constant $\gamma$ in the new expression seems to play the rôle of an index of the diurnal changeability of atmospheric stirring at the locality.

(iii) Listing the four constants $A_{0}, A, \gamma$ and $\varepsilon$ advantages for the specification of the local climatological conditions.

\section{Acknowledgement}

The writer wishes to express his sincere thanks to Prof. T. Namekawa, the Director of Meteorological Research Institute, Kyoto University, for his kind guidance.

\section{References}

1. Johnson, N. K. and Heywood, G.S.P. (1938): An investigation of the lapse rate of temperature in the lowest hundred meters of the atmosphere. Geophys. Mem., Met. Off., London, No. 77.

2. Brunt, D. (1932): Notes on radiation in the atmosphere. I. Quart. J. R. Met. Soc. London, Vol. 58. p. 408.

3. Okada, T. (1931): Climate of Japan. Central Met. Obs., Tokyo, pp. 295-99.

4. Shaw, N. (1936): Manual of Meteorology, Vol. II. Cambridge University Press, London, pp. 60-81.

5. Hann-Süring (1939): Lehrbuch der Meteorologie, Erster Band. Willibald Keller, Leipzig, pp. 114, 115 and 140.

6. Woeikof, U. (1887): Die Klimate der Erde, Tab. I and II. 